Running Head: METHODS IN MW RESEARCH

\title{
THE SCIENTIFIC STUdy OF PASsive THINKING THE METHODOLOGY OF MIND WANDERING RESEARCH
}

Samuel Murray ${ }^{\mathrm{a}}$, Zac Irving ${ }^{\mathrm{b}}$, Kristina Krasich ${ }^{\mathrm{c}}$

aDepartment of Psychology \& Neuroscience, Duke University, Durham, NC, USA

bepartment of Philosophy, University of Virginia, Charlottesville, VA, USA 'Center for Cognitive Neuroscience, Duke University, Durham, NC, USA

*Forthcoming in Philosophy \& Neuroscience, F. De Brigard \& W. SinnottArmstrong (Eds.). Cambridge, MA: MIT Press.

\section{Author Note}

Correspondence may be directed to Samuel Murray, Department of Psychology \& Neuroscience, Duke University, 417 Chapel Dr., Durham, NC, 27708. Email: samuel.f.murray@duke.edu 


\title{
METHODS IN MW RESEARCH
}

\begin{abstract}
In this chapter, we survey methodological challenges in the empirical study of mind wandering and provide a metaphysical framework that begins to address these challenges. We argue that mind wandering is a passive manifestation of agency - passive because people cannot mind wander on command and a manifestation of agency because the onset, progression, and content of mind wandering often exhibits direct sensitivity to personal concerns and plans. To measure passive thinking, researchers must ask, "Is your mind wandering?" Worries about this self-report methodology have encouraged researchers to develop "objective" measures of mind wandering through eye tracking and machine learning techniques. These "objective" measures, however, are validated in terms of how well they predict self-reports, which means that purportedly objective measures of mind wandering retain a subjective core. To assuage worries about self-report (and, ultimately, vindicate objective measures of mind wandering), we offer a metaphysical account of mind wandering that generates several predictions about its causes and consequences. This account also justifies different methods for measuring mind wandering.
\end{abstract}




\section{METHODS IN MW RESEARCH}

\section{Introduction}

Chances are, at some point when you're reading this, your eyes will move across the page while your mind is elsewhere. This is likely true even if you really want to stay focused on what we have to say. People's ability to remain vigilant toward any one thing is remarkably flawed-the mind is rich with internal thoughts, concerns, simulation, and feelings that can pull our attention away. Of course, sometimes you can actively shift attention. If you get bored, you might look at your phone to check email or social media. This kind of attention shift is an active mental phenomenon, as opposed to the more passive mental phenomenon of having one's attention drift away.

Mental life involves a dynamic coordination of these active and passive elements. You can decide whether to go to the store before or after work, deliberate on what to purchase, and intentionally buy the fruit instead of the chips (active phenomena), but you cannot easily manage your desire to eat chips or your belief that eating them will make you happy (passive phenomena). With regards to your attention span (assuming you are still with us), you may have decided to read this chapter, but that doesn't mean your desires to keep up with work or friends won't distract you.

Instead of reading carefully throughout, your mind will sometimes wander. It might wander to an upcoming test, a dinner out with friends last weekend, or a song you recently heard. Wherever it wanders, your mind will be wandering away from whatever we're saying. This isn't something you'll decide to do, but you will catch yourself doing it from time to time. For this reason, 


\section{METHODS IN MW RESEARCH}

mind wandering falls on the passive side of the active/passive divide. This isn't a definition; instead, it's an example that illustrates the phenomenon's passivity.

Special methods are often required to measure passive phenomena like mind wandering or dreaming (Windt, 2015; Irving, 2018). In particular, the sciences of passive thinking often require self-reports or retrospective assessments of the content or character of one's mental states. However, philosophers and cognitive scientists have raised epistemic worries about selfreport. It is therefore unclear whether we have an adequate methodology to empirically study mind wandering.

Our solution to this problem proceeds through a metaphysical account of mind wandering. We explain how mind wandering fits into the wider fabric of human agency, which makes sense of the causes and conditions of mind wandering. These can be leveraged into a (limited) defense of self-report methods used to study mind wandering.

Our paper has six parts. We first describe the central role of self-report in the rapid expansion of mind wandering research over the last 20 years $(\S 1)$. We next argue that the passivity of mind wandering explains why self-report is necessary for its study $(\$ 2)$, which may raise skeptical worries about the veracity of mind wandering research (§3). We then consider whether "objective" methods (§4) or studies of "intentional mind wandering" (§5) can obviate the need for self-report (spoiler: they can't). Finally, we propose a metaphysical solution to the epistemic problems of self-report (§6).

\section{§1: Methodological Shifts}




\section{METHODS IN MW RESEARCH}

Two methodological innovations explain why mind wandering came to prominence in cognitive psychology. First was the discovery of the so-called "default network", a set of brain regions associated with both rest and mind wandering. Of equal importance was the revival of self-report methods to measure the wandering mind. In this section, we discuss why these two innovations are central to the history of mind wandering research.

Twenty years ago, almost nobody in cognitive psychology or neuroscience talked about mind wandering (notable exceptions include Antrobus, 1968; Giambra, 1995; Wegner, 1997). Presently, each of the last five years has seen over 100 articles published on mind wandering. One might assume that the reasons for this shift concern the importance of mind wandering itself. Mind wandering occupies a significant portion of our waking thoughts (Kane et al., 2007; Seli, Beaty et al., 2018). It is associated with a range of costs, including higher rates of car crashes (Yanko \& Spalek, 2014; Gil-Jardiné et al., 2017), occupational accidents (Warm, Parasuraman, and Matthews, 2008), and general negative affect (Killingsworth \& Gilbert, 2010). ${ }^{1}$ It also has benefits for self-control (Gorgolewski et al., 2014), planning (Baird, Smallwood, \& Schooler, 2011) and creativity (Preiss

\footnotetext{
${ }^{1}$ The Killingsworth \& Gilbert (2010) study enjoys some prominence in the mind wandering literature for being one of the first large-scale experience sampling studies of mind wandering published in a prestigious venue. The paper is cited mainly for two findings: (1) the results that $30-50 \%$ of waking thoughts are mind wandering, and; (2) the association between mind wandering and negative affect. However, both results have been challenged recently. Some studies have shown that the frequency of mind wandering varies as a function of the response options provided to indicate mind wandering. Based on how self-reports are interpreted, mind wandering can constitute anywhere from 18-60\% of waking thoughts (Seli, Beaty, et al., 2018). Moreover, the association with negative affect fails to distinguish between different kinds of mind wandering (intentional/unintentional) and does not consider relevant trait-level moderators (e.g., mindfulness; see Wang, Xu, Zhuang, \& Liu, 2017). Reanalysis of the Killingsworth \& Gilbert (2010) data shows that accounting for interest in the content of off-task thoughts reveals a positive association between mind wandering and positive affect (Franklin et al., 2013-a). This shows that the results of the Killingsworth \& Gilbert (2010) study should be viewed within the context of recent developments and criticisms.
} 


\section{METHODS IN MW RESEARCH}

et al., 2016; Gable, Hopper, \& Schooler, 2019) (for review, see Smallwood \& Schooler, 2015). But the importance of mind wandering cannot explain its increase in prominence. After all, mind wandering was just as pervasive and had the same costs and benefits twenty years ago. Why, then, have the last two decades ushered in so much new research on mind wandering? Two methodological innovations deserve the lion's share of credit.

One innovation was the discovery of the so-called "Default Mode Network". In the early 2000s, researchers discovered that the brain has a "default" network that becomes considerably more active during moments of rest or inactivity than when subjects perform tasks (Raichle, 2015). ${ }^{2}$ This helped to spur interest in studying what the brain is doing when it's not engaged in a task. In other words, what is the brain doing when "resting?" This marked an exciting departure from the norm in cognitive psychology and neuroscience, which was to exclusively study the cognitive processes that support task performance (Irving, 2018; Callard, Smallwood, \& Marguiles, 2011).

Over time, researchers realized that the Default Mode Network subserves spontaneous internal cognition (Buckner, Andrews-Hanna, \& Schacter, 2008) and that Default Mode activity increases when people's minds are wandering (Christoff et al., 2009). Initially, these results suggested that mind wandering might reflect a default state of human cognition: the unperturbed stream of thought. That suggestion turned out to be overly simplistic, due to evidence that the default network can support goal-directed cognition (Spreng et al., 2010) and

\footnotetext{
${ }^{2}$ Shulman et al. (1997) provided the initial characterization of the Default Mode Network by contrasting activations in control states from activations in task states in PET studies. Follow-up studies confirmed the identity of the network (Binder et al., 1999; Mazoyer et al., 2001).
} 


\section{METHODS IN MW RESEARCH}

that other networks (notably the executive) are active during mind wandering (Fox et al., 2015; see Klein, 2012 for a philosophical discussion). Still, the discovery of the Default Mode Network helped mind wandering emerge as a research topic. It set the stage for observational experiments that were primarily concerned with studying what the brain does when one is not explicitly engaged in goal-directed thinking.

Mind wandering science also benefited from a second methodological innovation: the development and refinement of self-report measures of mind wandering. Most studies of mind wandering in the lab and everyday life use a self-report method called "retrospective thought sampling" (Smallwood \& Schooler, 2015). In these studies, subjects are periodically interrupted as they perform tasks in the lab or go about their daily lives. Subjects are then given a "thought probe" that asks them questions about their immediately preceding experiences (Figure 1). For example, one influential study asked subjects whether they agree that "At the time of the beep [the thought probe], my mind had wandered to something other than what I was doing" (Kane et al., 2007). Subjects who answered "yes" were classified as mind wandering.

Scientists have relied on these self-report methods to discover many characteristics of mind wandering, including (but not limited to) its frequency, costs, benefits, role in education, and its relationship to working memory, affect, episodic thinking, mindfulness, and the stream of thought (see Smallwood and Schooler, 2015; Christoff et al., 2016 for reviews). Indeed, the vast majority of our knowledge of mind wandering is owed (at least in part) to self-report. In the next section, we explain why. 


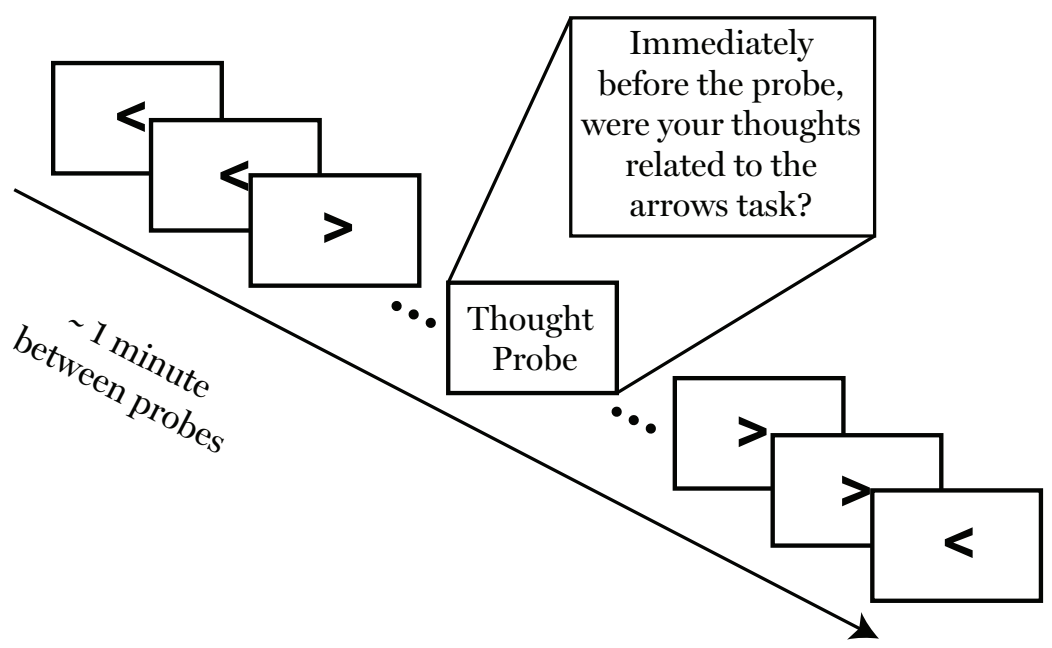

Figure 1: Retrospective thought sampling in a laboratory study (example). Subjects are interrupted by a thought probe on average once a minute. They are then asked whether their immediately preceding thoughts are related to the laboratory tasks. If not, their thoughts are classified as mind wandering. Reproduced with permission from Philosophy Compass.

\section{§2: Self-Report and Passive Phenomena}

Self-report is central to mind wandering research. In this section, we explain why this is due to the passivity of mind wandering. Specifically, we build on an argument from Irving (2018). Irving notes that cognitive psychologists typically study a cognitive process by giving subjects a voluntary task that activates that process. But because mind wandering is passive, no voluntary task initiates mind wandering. So, psychologists need a "task-free" method to study mind wandering. The best "task-free" method is self-report.

Here is our expanded version of Irving's argument:

1) If a cognitive process or state $\phi$ cannot be voluntarily initiated and does not reliably sub-serve the performance of a task, then the psychological study of $\phi$ requires self-report.

2) Mind wandering cannot be voluntarily initiated.

3) Mind wandering does not reliably sub-serve the performance of a task.

4) Therefore, the psychological study of mind wandering requires selfreport. 


\section{METHODS IN MW RESEARCH}

The remainder of this section offers support for these premises.

\section{\$2.1: Processes and Reports (Premise 1)}

Cognitive psychology often relies on experimental tasks to avoid the need for self-report. Let's say that a cognitive psychologist wants to study a cognitive process or state $\phi$. She will typically design an experimental task $\boldsymbol{\tau}$, where $\boldsymbol{\tau}$ is a voluntary action that is known to activate $\phi$. Our experimenter then has no need to ask subjects to self-report on whether they use process $\phi$ in the experiment. For we already know that anyone who performs task $\boldsymbol{\tau}$ activates process $\phi$ ! We call this approach "task-based psychology".

Tasks can activate a psychological process or state in two ways, depending on how directly one can control the process or state. First, some tasks exploit the fact that subjects can voluntarily initiate a psychological process or state. We'll say that an agent can voluntarily initiate $\phi$ if and only if she can bring about the occurrence of $\phi$ immediately by deciding, choosing, or willing to make $\phi$ obtain (see Adams, 1985: 8; cf. van Inwagen, 1989: 410). One example of the use of voluntary initiation is how psychologists use a "Go/No Go" task to study inhibitory processes (Lappin \& Eriksen, 1966; Logan, 2015). Subjects respond quickly to targets (e.g. "Go" signs) and withhold their response when they receive a stop signal (e.g. "Stop" signs). Because the task is timed, subjects typically begin to respond as soon as they see a stimulus, even if it is a stop signal. In stop trials, they then have to inhibit their response. Psychologists use Go/No Go tasks to study the psychological process of inhibiting an ongoing action. 


\section{METHODS IN MW RESEARCH}

Subjects can voluntarily initiate this sort of inhibition. So, anyone who completes the Go/No Go task will voluntarily activate the process in question.

Psychologists cannot use this direct method to study passive states and processes such as beliefs, desires, or dreaming. Agents cannot voluntarily initiate these passive states or processes because they can neither come to be in these states or bring about the occurrence of these processes immediately. ${ }^{3}$ At most, agents can indirectly be in some passive state or bring about the occurrence of a passive process $\phi$ by performing another action that she knows is likely to bring it about that $\phi$. Suppose you don't now desire to eat a tomato, for example. You cannot simply decide or choose to have that desire in a way that immediately and directly causes you to want a tomato. You can do things that make the desire more likely, such as googling pictures of caprese salads. But this amounts to only indirectly controlling your desires.

Task-based psychologists can sometimes use indirect methods to study passive states and processes. Sometimes, a passive state or process $\phi$ will subserve the voluntary performance of a task $\boldsymbol{\tau}$. If so, psychologists can ask subjects to voluntarily perform $\tau$ in order to indirectly activate $\phi$.

Consider, for example, how psychologists use spatial cueing paradigms (Posner, 1980) to study the effects of participant's beliefs on visual attention. Beliefs are passive, in so far as one cannot directly choose or decide to believe something (van Fraassen, 1984). But spatial cueing tasks manipulate subjects' beliefs about the location of a target stimulus. Participants are assigned to one of

\footnotetext{
${ }^{3}$ Whether direct voluntary control is necessary for action is contentious. The authors disagree on this point. But we hope to show that direct voluntary control is relevant to the methods of taskbased psychology.
} 


\section{METHODS IN MW RESEARCH}

three conditions. In one condition, a peripheral cue is presented indicating the location of the target stimulus (this is called the congruent condition). In another condition, the peripheral cue is presented in a location that differs from the target stimulus (the incongruent condition). In the control condition, no peripheral cue is presented. Fixation occurs much more quickly in congruent conditions relative to incongruent conditions (Israel, Jolicoeur, \& Cohen, 2018). This suggests that participants with true beliefs about the target location outperform subjects with false beliefs.

Belief, though passive, can be studied within the standard task-based experimental paradigm because we understand something about how belief produces action. Part of what it is to be a belief is to play a certain causal role in the production of action and a normative role in the explanation of action (Stalnaker, 1984: 4-5, 82). Paradigmatically, the desire G, coupled with the belief that A-ing is a means to realize G, will cause one to begin A-ing (Audi, 1979). When we know about someone's actions and desires, we can therefore use this schema to infer someone's beliefs. For example, visual fixation is an action (or a component of an action) that subjects use to complete an experimental task. So, we can reliably infer that subjects form beliefs about the best location for visual fixation. Crucially, we can make this inference even though belief is passive because we know how beliefs tend to sub-serve action.

We argue that there are two conditions under which psychologists can use task-based methods to study a cognitive process or state $\phi$. First is when subjects can voluntarily initiate $\phi$. Second is when $\phi$ reliably sub-serves the performance 


\section{METHODS IN MW RESEARCH}

of a task that one can voluntarily initiate. If neither of those conditions obtain, psychologists must use the methods of task-free psychology: self-report.

\section{§2.2: Tasks and Mind Wandering (Premises $2 \mathcal{E} 3$ )}

Premise 2 in our argument says that one cannot voluntarily initiate mind wandering. This is intuitive. People cannot make their minds wander at the drop of a hat and often catch their minds wandering (just as you can catch yourself dozing off). People can put themselves in a position that makes mind wandering likely, such as reading a boring book. But at the end of the day, you must let mind wandering come to you.

Premise 3 says that mind wandering does not reliably sub-serve the voluntary performance of a task. Unlike belief, researchers cannot ask subjects to perform tasks that require mind wandering because there are no such tasks. Our argument for this premise differs, depending on how you define mind wandering (cf. Irving, 2018 for similar arguments).

Most psychologists define mind wandering as task-unrelated thought. In a laboratory, this means that our wandering thoughts are (by definition) unrelated to the task assigned by the experimenter. But if thoughts sub-serve an experimental task, then they are related to that task. By definition, any thoughts that sub-serve the experimental task are not mind wandering, according to the standard definition.

Others define mind wandering in terms of its dynamics, rather than its relationship to an ongoing task (Irving, 2016; Christoff et al., 2016; Sripada, 2018). Dynamic views focus on how mind wandering unfolds over time, meandering 


\section{METHODS IN MW RESEARCH}

from one topic to another. Such views contrast mind wandering with goaldirected thinking, which remains focused on the agent's task. Irving (2016) appeals to guidance to explain the dynamic difference between mind wandering and directed thinking. During goal-directed thinking, for example, the agent guides her attention to remain on task-relevant stimuli. During mind wandering, in contrast, the agent's attention is unguided and thus free to meander from topic to topic.

We can now explain why no task can reliably recruit mind wandering. Part of what it means to perform a task is to guide your attention to thoughts that are relevant to that task. So, any thoughts that sub-serve an agent's task will be thoughts that she guides her attention towards. Therefore, those thoughts will not constitute mind wandering.

We now have an argument that explains why mind wandering research relies on self-report. Agents cannot voluntarily initiate mind wandering nor can mind wandering reliably sub-serve the performance of a task. The methods of task-based psychology are therefore ill-suited to study the wandering mind. Mind wandering researchers must instead rely on task-free methods: namely, self-report.

\section{§3: Skepticism about Self-Report}

Self-report is central to the science of mind wandering. At bottom, mind wandering research fundamentally requires that we ask people to reflect on what's going on in their minds. You might think this is a serious cause for concern. Empirical evidence suggests that people are notoriously unreliable when they make judgements about their own minds. The situation is particularly 


\section{METHODS IN MW RESEARCH}

bad when we use survey responses as data points. Survey responses are subject to framing effects (Sinnott-Armstrong, 2008), social desirability biases (Robins \& John, 1997), and simple misunderstanding of the questions being asked (Cullen, 2010). Moreover, people are bad at remembering their responses to surveys, raising the question of whether responding to surveys activates reliable, reasonsresponsive processes. Hall and colleagues showed this when they reversed people's responses to a moral and political opinion survey and got people to defend their reversed positions (Hall, Johansson, \& Strandberg, 2012)!

Survey's about experience are notoriously unreliable. Fortunately, such surveys differ from thought sampling methodology in important ways. Thought probes do not interrogate why you are mind wandering, just whether you are. So, while people exhibit unreliability in making process assessments ("Why are you in a particular mental state?"), mind wandering research requires state assessment ("Are you in this particular mental state?"). Furthermore, thought sampling questions do not ask about obscure technical concepts like knowledge or freedom. Rather, they ask about a pervasive and familiar experience: whether your mind was wandering or not. Finally, thought-sampling methods ask about your immediately preceding experiences, rather than to report on what your experiences are like in general. Such methods may therefore avoid the distorting effects of memory (Windt, 2016).

We have empirical reasons to trust self-reports of mind wandering. Mind wandering research shows surprising consistency in self-reports of mind wandering. There is emerging evidence of convergent validity between selfreports and third-party assessments of mind wandering (Mills et al., 2018). Selfreports of mind wandering consistently correlate with various indirect measures 


\section{METHODS IN MW RESEARCH}

of mind wandering. Some of these are behavioral, such as performance errors (McVay \& Kane, 2009), comprehension failures (Schooler, Reichle, \& Halpern, 2004), eye movements (Uzzaman \& Joordens, 2011), and changes in response variability (Seli, Smallwood, Cheyne, \& Smilek, 2015). Other measures are physiological, including evoked response potentials (Smallwood, Beach, Schooler, \& Handy, 2008), pupil dilation (Franklin et al., 2013-b), eye blink rate (Smilek, Carriere, \& Cheyne, 2010), and changes in brain activity (Christoff et al., 2009).

None of this is decisive. Global skeptical arguments about even the simplest experiential reports (Schwitzgebel, 2008) are notoriously hard to defuse (see Sosa, 1994). Furthermore, there are critics of self-report within the science of mind wandering (just as there are critics of nearly any empirical method).

One issue concerns the distorting effects of thought probes. Studies that present probes too often may disrupt the natural flow of thought in at least four ways. First, probes may reorient attention to task demands and reduce mind wandering (Seli, Carriere, Levene, \& Smilek, 2013; although see Robison, Miller, \& Unsworth, 2019). Second, hyper-probing can lead to increased meta-awareness of one's thoughts, which itself alters the occurrence of mind wandering (Zedelius, Broadway, \& Schooler, 2015). Third, this increased meta-awareness is a problem in itself: it inflates assessments of the degree to which mind wandering is accompanied by meta-awareness. Finally, laboratory tasks are often structurally dissimilar from real-world tasks, meaning that rates of mind wandering in the lab are difficult to translate into predictions of rates of mind wandering in the real world (see Murray, Krasich, Schooler, \& Seli, In Press). 


\section{METHODS IN MW RESEARCH}

Another methodological problem concerns how we define mind wandering. The vast majority of self-report studies operationally define mind wandering as task-unrelated thought (Mills et al., 2018). Many task-unrelated thoughts overlap with mind wandering. If your mind wanders from topic to topic as your eyes scan this page, for example, your thoughts are unrelated to the task of reading.

Yet the standard view has come under fire from multiple fronts. Taskunrelated thought is a broad and heterogeneous category (Irving, 2016; Christoff et al., 2016). While your eyes mindlessly scan the page, for example, you might diligently do mental math for your statistics class. Or you might obsessively ruminate on a fight you just had with your friend. Such focused thinking seems to contrast with the meandering thinking characteristic of mind wandering. Furthermore, it's not clear how the standard view handles cases of mind wandering in the absence of a task. Your mind can wander while you are resting on the beach. But then you don't have a task to wander away from (Seli et al., 2018; Irving, 2016). ${ }^{4}$

Cognitive scientists have recently proposed alternatives to the standard definition of mind wandering. But it is still an open question how amenable those new theories are to self-report. The dynamic view says that mind wandering is relatively unconstrained thought, which freely meanders from topic to topic (Irving, 2016; Christoff et al., 2016; Sripada, 2018: see §2). Yet the

\footnotetext{
${ }^{4}$ Irving (2016) argues that we can modify the definition of mind wandering as task-unrelated thought to avoid the problem of rest. Specifically, we can define mind wandering as thought that is not related to any task the subject is currently performing. If a subject is performing no task, her thoughts will trivially be mind wandering. Yet there are other problems with this version of the definition.
} 


\section{METHODS IN MW RESEARCH}

empirical study of the dynamic stream of thought is still in its infancy. One study found that reports of freely moving and task-unrelated thought are orthogonal in daily life and that the former independently predicts affect (Mills et al., 2018). Ongoing work tells a nuanced story. One study found that unique electrophysiological signatures are differentially associated with freely moving, directed, and task-unrelated thought (Kam, Irving, Mills, et al., Under Preparation). However, another study failed to find predicted relationships between freely moving thought and various clinical pathologies (OCD, depression, and anxiety), as well as a negative correlation between freely moving thought and creative idea generation (Smith et al., Under Preparation). This might suggest that the probes used to assess freely moving thought do not measure constructs that are readily interpretable.

Others argue that mind wandering is a heterogeneous construct with multiple overlapping attributes that no single instance of mind wandering fully exemplifies (Seli et al., 2018). This argument depends on the (contentious) claim that no single definition of mind wandering picks out an extensionally adequate concept. On this basis, some have begun to propose alternative subjective measures of mind wandering that reflect the inherent heterogeneity of the construct (Murray et al., In Press).

Our review suggests that psychologists and philosophers have both worried about our current self-report measures of mind wandering. But the solutions to these problems almost exclusively involve the refinement of selfreports. You may wonder: can we do better?

§4: Intentional Mind wandering 


\section{METHODS IN MW RESEARCH}

We find ourselves in a pickle. On the one hand, we argue that the scientific study of mind wandering requires self-report. On the other hand, you might be skeptical of self-report methods. You may therefore ask: can we break out of the cycle of self-report?

Our master argument in $\S 2$ suggests that mind wandering research must rely on self-report. Recall that our argument is as follows:

1) If a cognitive process or state $\phi$ cannot be voluntarily initiated and does not reliably sub-serve the performance of a task, then the psychological study of $\phi$ requires self-report.

2) Mind wandering cannot be voluntarily initiated.

3) Mind wandering does not reliably sub-serve the performance of a task.

4) Therefore, the psychological study of mind wandering requires selfreport.

If you think mind wandering research can "break the cycle" - that is, can do without self-report - then there must be something wrong with this argument. In the next two sections, we consider two objections to our argument. The first targets premises 2 and 3, arguing that so-called "intentional mind wandering" can be either voluntarily initiated or sub-serve a task. The second targets premise 1 , on the grounds that "objective" measures allow us to study mind wandering without tasks or self-report. We turn first to the objection from intentional mind wandering.

Premises 2 and 3 state that no voluntary task can activate mind wandering, either directly or indirectly. You might resist this conclusion based on empirical evidence for "intentional mind wandering". People frequently report intentional mind wandering - that is, letting their minds wander on purpose - in the laboratory (Seli, Risko, Smilek, \& Schacter, 2016), everyday life (Kane et al., 2007). Empirical research suggests that the folk think mind 


\section{METHODS IN MW RESEARCH}

wandering can be intentional (Irving et al., Under Review). Furthermore, intentional and unintentional mind wandering seem to reflect independent stateand trait-level variables (Seli, Risko, \& Smilek, 2016).

You might find the possibility of intentional mind wandering intuitive. While you're reading this paper, for example, you might defiantly turn your head away from the page and let your thoughts drift from topic to topic. You might then argue that intentional mind wandering is a voluntary task that activates mind wandering. If so, then task-based methods may be able to measure mind wandering after all (contra premises 2 and 3 ).

Our response to this objection depends on how you define mind wandering. Consider the task-unrelated thought theory of mind wandering. On this view, intentional mind wandering would consist in you intending to have task-unrelated thoughts. But in intending to have such thoughts you acquire a task - namely, letting your mind wander. So, your thoughts are task-related, and not mind wandering. Intentions generate tasks, so it's impossible to intend to think task-unrelated thoughts (see Murray \& Krasich, In Press).

Intentional mind wandering might be more methodologically useful, if we adopt a dynamic theory of mind wandering. We'll focus on Irving's dynamic theory of mind wandering as unguided thought. Like Murray and Krasich, Irving denies that one can directly voluntarily initiate a wandering stream of thoughts. Unlike raising one's arm, for example, one cannot just choose or decide to begin mind wandering.

But Irving (under submission) argues that one can voluntarily maintain mind wandering through a process called meta-control. According to Irving, one cannot guide a wandering stream of thoughts to any particular topic; this would 


\section{METHODS IN MW RESEARCH}

be to stop your mind from wandering. But you can use meta-control to keep your thoughts from becoming guided to any particular topic. Someone who exerts meta-control will notice when she begins to fixate on a topic and let her mind wander once more. Meta-control is similar to the kinds of contemplative techniques that artists (Green, 2010) and meditators (Lutz et al., 2008) use to maintain freely moving streams of thought (for a view of intentional mind wandering based on these artistic and meditative practices, see Arango \& Bermúdez, Manuscript).

Can meta-control ground a task-based science of mind wandering? You might think so: perhaps we can recruit participants (like artists and meditators) who are skilled at maintaining a wandering stream of thoughts or train ordinary people to do so. We can then examine the effects and correlates of mind wandering by simply asking participants to perform the "task" of maintaining their mind wandering.

Unfortunately, this interesting method is limited in two ways. First, even trained participants cannot voluntarily initiate mind wandering. They can simply maintain mind wandering once it has already begun. Thus, unlike normal taskbased methods, we cannot use the "task" of letting your mind wander to track the onset of a stretch of mind wandering. Second, and more importantly, the ability to maintain a wandering stream of thoughts requires a specialized process - meta-control - and likely requires specialized training. Meta-controlled mind wandering may therefore differ in important ways from mind wandering in the absence of meta-control. But there is no way to assess this without the use of selfreport. Again, we find that self-report is indispensable for the scientific study of mind wandering. 


\section{METHODS IN MW RESEARCH}

Our discussion thus far shows the limits of methods that require direct voluntary control over mind wandering. If mind wandering is task-unrelated thought, such methods are conceptually incoherent. If mind wandering is unguided thought, such methods cannot tell us about mind wandering in general unless we use self-report. But perhaps we will have more luck with methods that exploit indirect voluntary control over mind wandering.

It is possible to indirectly control mind wandering: you can perform some other voluntary task $\boldsymbol{\tau}$ because you know that $\boldsymbol{\tau}$ reliably leads to mind wandering. Suppose that after a long day of studying, you want to let your mind wander to clear your head. You might do this by taking a shower, or washing the dishes, which are the kinds of boring tasks that reliably lead to mind wandering (Mason et al., 2007; Smallwood et al., 2009). You might assume that indirect voluntary control provides a route to the task-based study of mind wandering. Rather than ask subjects, "was your mind wandering", for example, you might simply give them the kind of boring task that reliably leads to mind wandering.

Baird et al.'s (2012) influential study of mind wandering and creativity employs this kind of indirect method. They tested whether mind wandering can lead to creative insights. This idea is intuitive: when you're stuck on a problem, for example, you might make progress by letting your mind wander in the shower. Baird et al. (2012) tested this idea by having subjects solve a creative problem, take a break, and then return to the same problem. During the break, subjects in the experimental condition performed an easy task known to induce mind wandering. Subjects in one control condition performed a difficult task known to reduce mind wandering. Baird et al. found that subjects who 


\section{METHODS IN MW RESEARCH}

performed the easy task were more creative after the break than those who performed the difficult task. So, they concluded that mind wandering facilitates creativity.

But Baird et al.'s indirect method makes it difficult to interpret their results (Irving, 2018). It is possible that easy tasks facilitate creativity more than difficult tasks because they lead to higher rates of mind wandering. But it is also possible that the effect of task-difficulty on creativity bypasses mind wandering

entirely. Easy tasks might lead to relaxation, whereas difficult tasks might lead to frustration. And this difference in affective state might be what drives creativity. This is not a problem that indirect task-based methods can solve. Baird et al.'s subjects do not voluntarily initiate mind wandering or perform a task that mind wandering sub-serves. Rather, they perform a task $\boldsymbol{\tau}$ that has two likely effects: mind wandering and creativity. Indirect methods alone cannot determine whether the effect on creativity is due to $\tau$ or mediated by mind wandering. To test for this mediation, we would need to ask subjects whether their minds are wandering during the break, and see whether those self-reported rates of mind wandering predict creativity. That is, we would need to rely on self-report.

Our discussion in this section shows that mind wandering researchers cannot use intentional mind wandering to make do without self-report. A careful study of intentional mind wandering might lead to the development of direct and indirect methods to study the wandering mind. But those methods at best complement self-report; they are not a replacement.

\section{§5: Establishing Objective Measures}




\section{METHODS IN MW RESEARCH}

We cannot exploit intentional mind wandering to ground a task-based science of the wandering mind. Premise 1 of our master argument states, roughly, that self-report is the best (perhaps the only) alternative to task-based methods. If so, it follows that mind wandering research must rely on self-report. You might object that there is a third alternative to task-based methods and selfreport. Tasks and reports are useful because they reliably indicate that a process such as mind wandering is active. If we can devise alternative indicators for mind wandering, then we can do without tasks or reports. This hope animates the search for "objective" measures of mind wandering.

Researchers have found various objective markers that correlate with reports of mind wandering, such as response times, task-accuracy, or eyemovements. One hope is that those objective markers can obviate the need for self-report; rather than ask subjects, "was your mind wandering?", the dream is simply to determine this by looking at her eyes!

After a careful review of objective methods, we argue that they cannot replace self-report for two reasons. First, current findings are mixed and likely impacted by idiosyncrasies of ongoing task demands and strategies. As such, an indisputable set of mind wandering-specific behaviors has yet to be established. Second, self-report is used to establish objective methods. Thus, "objective" methods actually extend, rather than replace, self-reports in the study of mind wandering.

\section{§5.1: Response times and performance accuracy}

Many laboratory studies of mind wandering have integrated thought probes into the Sustained Attention to Response Task (SART; Robertson, Manly, 


\section{METHODS IN MW RESEARCH}

Andrade, Baddeley, \& Yiend, 1997), which is a task historically used to study vigilance. The SART requires participants to respond to nearly all stimuli and withhold responses to infrequent targets, and errors of commission and faster responses times (RT) are generally taken as evidence of vigilance lapses. That is, participants perform the task more quickly because they rely on their prepotent responses to stimuli rather than making on-the-fly adjustments, and errors of commission are thought to occur due to attenuated response inhibition.

In many studies, self-reported mind wandering during the SART is correlated with worse task performance and faster RT (e.g., McVay \& Kane, 2011; Kane \& McVay, 2012; Thomson, Besner, \& Smilek, 2015). These findings seem consistent with frameworks of mind wandering that characterize it in terms of executive control failures (McVay \& Kane, 2010) or lapses in vigilance (Spruyt et al., 2019). The link with faster RT is particularly intriguing as a potential realtime, thought probe independent index of mind wandering: with faster RT, the more likely a participant in currently mind wandering.

Unfortunately, this framework is too simple and, at times, inaccurate. Indeed, a few studies have found that self-reported mind wandering was associated with significantly slower RT (Baird et al., 2014; Bastian \& Sackur, 2013). Factors contributing to these discrepancies are unclear, but may include a variety of interrelated factors pertaining to differences in thought content, progression, and meta-awareness of mind wandering (Bastian \& Sackur, 2013). Another possibility is that RT variability, rather than speed, is actually a better indicator of mind wandering (Bastian \& Sackur, 2013; Seli, Cheyne, \& Smilek, 2013; Thomson, Seli, Besner, \& Smilek, 2014), but others have failed to find this effect (e.g., McVay \& Kane, 2011). Therefore, the collective evidence does not eliminate 


\section{METHODS IN MW RESEARCH}

the link between mind wandering and RT in the SART, but it does call into question RT as a reliable indicator of mind wandering across experimental conditions. In other words, the link between RT and mind wandering is highly influenced by specific task parameters, which challenges the utility of using RT as a single, reliable behavioral index of mind wandering.

A tempting hypothesis, then, is that changes in RT relative to task performance could improve predictive capability. Supportive evidence of this has shown that as an iterated task progressed, the frequency of reported mind wandering increased, the observed differences in associated RT become more robust and accuracy also decreased (e.g., Krimsky, Forster, Llabre, \& Jha, 2017).

Even this framework, however, is not without its challenges, especially because people can perform simple tasks accurately enough even while mind wandering, such as mind wandering while driving home from work. For example, Brosowsky, Murray, Schooler, \& Seli (Under Review) measured rates of mind wandering during an implicit learning task. They found that as participants learned the task, RTs became faster and depth of mind wandering increased. Performance, however, improved throughout the task (consistent with the task becoming learned). Thus, some tasks are such that as they become automatized, mind wandering does not interfere with their performance. RTs and performance are uninformative indicators of mind wandering in these situations.

Furthermore, people exhibit signs of strategic mind wandering, especially in predictable or familiar task environments (Seli, Carriere, et al., 2018). Seli and colleagues had participants watch a clock hand that moved in discrete steps, completing one revolution every 20 seconds. The instructions were simple: press 


\section{METHODS IN MW RESEARCH}

the Spacebar on the keyboard whenever the clock hand reached the " 12 " (upright) position. Using thought probes to measure the occurrence of mind wandering, they found that mind wandering was significantly more likely to occur when the clock hand was in the second or third quadrant ("3" - "9") than the first or fourth quadrants. People began mind wandering when they knew they didn't need to pay attention, and they returned to the task when they knew they needed to. Accordingly, there was no relationship between the rates of reported mind wandering and task accuracy.

Collectively, findings from Seli et al. (2018) imply that people can continue monitoring the task and remain aware of the task environment even when they report mind wandering. Again, we see that the link between mind wandering and potential behavioral indices is highly influenced by specific task parameters and might not be a reliable indicator of mind wandering across contexts.

\section{§5.2: Gaze behaviors}

A growing body of research has investigated eye movements as a potential behavioral index of mind wandering. Motivating this approach, eye movements are closely linked to the visual processing priorities of the visual system (e.g., Just \& Carpenter, 1976; Kowler, Anderson, Dosher, \& Blaser, 1995).

This is in part due to the structural and functional limitations of the visual system in virtue of the anatomy of the eye, the organization of neurons in the primary visual cortex, and strict capacity limits on attention and working memory. People tend to look wherever they are attending (rare exceptions include covert shifts of attention) in such a way that best serves ongoing task goals. 


\section{METHODS IN MW RESEARCH}

During mind wandering, however, the visual system becomes, to some degree, perceptually decoupled from sensory inputs (Schooler et al., 2011; Smallwood, 2013). Neuroscientific measures support this idea. For instance, electroencephalography (EEG) studies have shown that self-reported mind wandering is associated with attenuated P1 event-related potential (ERP) component amplitude (Baird et al., 2014; Kam et al., 2011; Smallwood, et al., 2008)— the ERP component associated with low-level visual processing (Hillyard, Hink, Schwentt, \& Picton, 1973). Mind wandering is also associated with attenuated cognitive processing of external stimuli, as indicated by an attenuated P3 ERP component (Barron, Riby, Greer, \& Smallwood, 2011). Considered together, findings indicate a reduction in processing external information related to mind wandering.

Changes in external processing during mind wandering, then, should result in corresponding changes in gaze behaviors. Accordingly, research has identified a number of changes in gaze behaviors associated with mind wandering, although results have been relatively mixed. To illustrate, as one of the first studies to investigate mind wandering-related gaze behaviors, Reichle, Reineberg, \& Schooler (2010) showed that the eyes tended to fixate on words for a longer duration of time before reports of mind wandering compared to reports of attentive reading. These longer fixations were not related to word length or frequency, as they are during attentive reading (Juhasz \& Rayner, 2006; Rayner \& Duffy, 1986; Reichle, Rayner, \& Pollatsek, 2003).

Findings from Reichle et al. (2010) suggests that longer fixation durations might be a promising objective measure of mind wandering, especially because this relationship has been replicated in other work using reading tasks (e.g., 


\section{METHODS IN MW RESEARCH}

Bixler, Blanchard, Garrison, \& D’Mello, 2015; Foulsham, Farley, \& Kingstone, 2013; Frank et al., 2015) as well as scene viewing tasks (Krasich et al., 2018). Others, though, have failed to replicate (Smilek, Carriere, \& Cheyne, 2010; Uzzaman \& Joordens, 2011) or have even found shorter fixations associated with mind wandering reports (Steindorf \& Rummel, 2020). Contributing factors for these discrepant findings might include task-specific features (Faber, Krasich, Bixler, Brockmole, \& D'Mello, in press; Franklin et al., 2013-b), such as the difficulty of the text, text presentation, and the length of time spent reading, all of which can impact aspects of mind wandering (Forrin, Risko, \& Smilek, 2019; Feng, D'Mello, \& Graesser, 2013). It would thus seem as though the relationship between mind wandering and gaze might be contingent on the idiosyncrasies of ongoing task demands.

To test this idea, Faber, Krasich and colleagues (in press) asked participants to complete a battery of computer-based cognitive tasks while their eye movements were measured. These tasks included the SART, listening to an audiobook (while looking at a central fixation), reading a narrative story, comprehending an illustrated text, viewing visual scenes, watching a recorded academic lecturer, and watching a narrative film. As such, the tasks varied across the extent of the visual stimuli as well as the visual and discourse processing demands. Accordingly, these tasks should demand very different gaze patterns during attentive viewing, and they purpose of the study was to examine whether the relationship between mind wandering and eye movements would also vary by task.

The findings showed just this contextual variance. Specifically, in tasks that required extensive sampling of the visual field (i.e., scene viewing, 


\section{METHODS IN MW RESEARCH}

comprehending an illustrated text, and reading), mind wandering was associated with fewer fixations. Depending on the task, these fixations were also longer and more dispersed. Conversely, in tasks that required more focused gaze (i.e., the SART, listening to an audiobook while looking at a central fixation, and watching a recorded academic lecture), mind wandering was associated with shorter and more dispersed fixations as well as larger saccades. These findings support the idea that the relationship between mind wandering and gaze behavior varies according to the idiosyncrasies of the task, highlighting the impact of taskspecific features.

Findings from Faber, Krasich et al. (in press) pose a challenge for initiatives attempting to use gaze patterns as a behavioral index of mind wandering. It is probably no surprise, then, that predictive modeling methods (such as those described in Yarkoni \& Westfall, 2017) have yet to identify a common set of gaze parameters that can be used across all tasks. Still, modeling eye movements to predict mind wandering within a task has some potential. Essentially, this approach considers a variety of changes in eye movements associated with reports of mind wandering in concert.

For instance, Faber, Bixler, \& D'Mello (2018) developed a gaze-behaviorbased, machine-learned model of mind wandering utilizing reading data from 132 undergraduate students across two universities (dataset from Kopp, D’Mello, \& Mills, 2015). Specifically, this "mind wandering detector" used train supervised classification models (the best model being a sequential minimization optimization (SMO) algorithm, an implementation of a support vector machine (SVM) classifier) of gaze behaviors associated with self-caught mind wandering (participants pressed a key on the keyboard when they caught themselves mind 


\section{METHODS IN MW RESEARCH}

wandering). The model included 62 global (content-independent) gaze features, such as the number, duration, and dispersion of fixations, the number of saccades (ballistic eye movements between fixations), and the number of blinks. The advantage to using such a robust set of features is that behaviors are considered in concert, rather than independently.

The model was validated using a leave-one-reader-out cross-validation method that trained the model on data from $n-1$ participants and tested the model on data from the remaining participant until all 132 served as a 'test' participant. The best model (SMO) had a weighted precision of $72.2 \%$ and a weighted recall of $67.4 \%$. Stated simply, this mind wandering detector could accurately (though not perfectly) predict self-reported mind wandering from gaze behaviors. Other have gone on to use this detector to predict the likelihood of ongoing mind wandering in real-time and intervene (by, e.g., asking readers to reread sections encountered while mind wandering) to improve comprehension (D'Mello, Mills, Bixler, \& Bosch, 2017; Mills, Gregg, Bixler, \& D'Mello, 2020).

Outside of the context of reading, Hutt et al. (2019) adopted an offline-toonline classification-verification approach to predict the likelihood of ongoing mind wandering within an artificial intelligence tutoring system (ITS). These authors first gathered data from 135 high school students who completed the ITS and responded to pseudo-randomly distributed thought probes (probe-caught mind wandering) as to whether they were on-task or off-task at a given moment. The authors then used Bayesian Networks to classify gaze behaviors associated with mind wandering (from a set of 57 global gaze parameters, 80 contentspecific parameters, and 8 features related to the human-computer interactions) and a leave-several-students-out cross-validation scheme (67\% of students were 


\section{METHODS IN MW RESEARCH}

used in the training set and 33\% were assigned to the test set) for 15 iterations. Findings showed accuracies (mind wandering $\mathrm{F}_{1}=.59$ ) were better than chance $\left(\mathrm{F}_{1}=.24\right)$, and this model could generalize to data collected from a controlled laboratory study.

Live mind wandering detection was then tested on a new sample of 39 high school students. Students completed the same ITS while mind wandering probabilities were generated. Two types of thought probes were distributed throughout the learning session: 1) a probe that was triggered by the mind wandering detector used to assess hits and false alarms and 2) pseudo-random probes used to identify missed mind wandering episodes. Findings showed that mind wandering detection (mind wandering $\mathrm{F}_{1}=.40$ ) was above chance $\left(\mathrm{F}_{1}=.24\right)$. Collective evidence from Hutt et al. (2019) again indicate accurate (though still imperfect) real-time mind wandering detection that can rely on gaze behaviors alone to predict mind wandering.

\section{§5.3: Limitations of Objective Methods}

Objective methods - particularly machine learning - provide a promising avenue for the study of mind wandering. For example, machine learning classifiers may allow us to detect mind wandering without disrupting the subject's task performance or spontaneous stream of thoughts. This would ease worries about how self-reports disrupt the thoughts they are designed to measure.

Yet even these "mind wandering detectors" do not remove the need for self-report. We have already reviewed one reason: objective measures of mind wandering are not always available and differ across task-contexts. But a more 


\section{METHODS IN MW RESEARCH}

fundamental reason is that so-called "objective" methods have a subjective core. Machine learning classifiers are initially trained to detect self-reported mind wandering. Researchers then validate a classifier on the basis of how well it detects self-reported mind wandering. Our review of the literature suggests that we may have to use self-report to re-train and re-validate our classifiers in different task contexts. Self-report is therefore still the epistemic foundation of objective measures of mind wandering (Irving, 2018).

Classifiers thus inherit many of the challenges of self-report methods. For instance, even supposing that the classifiers perfectly detect self-reported mind wandering (which they don't), they are all trained to detect one operational definition of mind wandering - task-unrelated thoughts. But we've seen that various researchers have criticized this definition (§3). Therefore, we can develop a more nuanced classifier - that detects the dynamics of thought, for example - only after we develop more nuanced self-report measures of mind wandering.

Our more fundamental point is that wholehearted skepticism about selfreport is not an option for mind wandering research. In section 3, we noted that philosophers and cognitive scientists have both questioned whether self-report can ever be a reliable method. We think the success of mind wandering science generates a powerful response to this brand of skepticism. But if skepticism still tempts you, "objective" methods should provide you no relief. For those methods are only as good as the self-reports that they are designed to track.

\section{§6: Functional Justification of Self-Report}

Mind wandering science cannot break out of the cycle of self-report. But that does not mean we must trust self-report blindly. Instead, we have empirical 


\section{METHODS IN MW RESEARCH}

and philosophical reasons to be confident in self-reports about mind wandering. We have already reviewed some of the empirical reasons for confidence (§3). Self-reports of mind wandering are remarkably consistent in their contents and their ability to pick out behavior, neural activation, and third-party reports. If self-reports were spurious, we should predict that this consistency would not arise.

We will now provide a philosophical argument for the reliability of selfreports. Recall earlier our discussion of how the functional role of belief plays an important role in supporting inferences about it in experimental contexts. We believe that understanding the functional role of mind wandering will be similarly helpful in vindicating some of the self-report methods used to measure mind wandering. Our argument has the following structure. We have independent reason to believe two leading (and compatible) theories about the function of mind wandering (related to plural goal pursuit and exploration). We note that each of those theories makes predictions about the contexts in which mind wandering should be most prevalent. Self-reports confirm those predictions. The fact that our best theories and self-report methods converge is reason to trust both theory and method.

Let us start by reviewing two theories about the function of mind wandering.

\section{§6.1: Plural Goal Pursuit}

The mind's tendency to wander is both salient and puzzling. Studies indicate that we spend a lot of time mind wandering (Seli, Beaty et al., 2018). Perhaps this is obvious from your ordinary experience. But take a step back and 


\section{METHODS IN MW RESEARCH}

this statistic is shocking. When the world is a dynamic, unpredictable, and dangerous place, why would any creature spend half their lives being inattentive? What function could mind wandering have that explains its prominence in our lives?

The first theory is that mind wandering enables scattered agents like us to plan our futures. Human beings have hierarchically structured sets of goals, commitments, and projects that they aim to complete over time scales of days, weeks, months, and even years. This requires balancing many different demands that these place on our time. For example, one must balance the demands of being a teacher, being a parent, being a friend, and so on. Navigating social space requires living up to the different goals and expectations associated with the various roles one occupies.

In addition to having lots of goals, people have relatively limited capacities. Some of these limitations are physical. The particularities of embodiment preclude us from moving in two opposite directions simultaneously. But some of these limitations are psychological. Visual attention does not extend much beyond about 5 degrees of arc. Working memory has severe capacity limits (Miller, 1956), items stored in working memory decay rapidly (Baddeley \& Hitch, 1974), and self-control exhibits depletion effects over short time-scales (Dang, 2018). These limits present obstacles to plural goal pursuit.

To do a lot with a little, people scatter their agency over time (see Amaya \& Murray, Under Review). Non-scattered agents act sequentially, and they can only start a new activity upon completing or abandoning current activity. Scattered agents, on the other hand, are capable of being engaged simultaneously 


\section{METHODS IN MW RESEARCH}

in various projects without explicitly acting on any particular project then and there. In this way, scattered agents act in such a way that their actions have distinct (non-overlapping) temporal parts (see Sorensen, 1985). While scattering action is an efficient solution to the problem of plural goal pursuit under conditions of computational limitation, scattered agency raises unique engineering problems. People must now balance focus on their present activities with keeping an eye on acting in the future.

Balancing consists in dynamically altering the allocation of psychological resources to fluidly pursue multiple goals simultaneously. At any point in time, there will be multiple, jointly incompatible ways of allocating one's psychological resources to pursuing distinct tasks. For example, do you focus on answering emails, editing a manuscript, or diving into some grading? You can't do all three at once, and you've got to do them all eventually. The marginal utility of focusing on any task diminishes over time. This creates pressure to switch to other tasks, the phenomenological correlate of which might be the experience of effort (Shenhav et al., 2017). However, the possibility of switching to a disengaged plural pursuit state can be beneficial, where people think about various goals without thinking too hard about any particular goal. This is especially true when current task performance is unlikely to improve with increased or sustained focus.

Mind wandering's first function is arguably to enable this disengaged plural pursuit state. ${ }^{5}$ On this view, mind wandering drifts between various

\footnotetext{
${ }^{5}$ The term 'disengaged' serves to distinguish mind wandering from multi-tasking, the latter of which is an engaged or committed form of plural goal pursuit. Roughly, in multi-tasking, someone explicitly commits to focusing on several tasks simultaneously. In mind wandering,
} 


\section{METHODS IN MW RESEARCH}

contents, though it is predominantly drawn to one's goals and concerns (cf. Klinger, 2013; Irving, 2016). Mind wandering, then, reflects a way of managing limited mental resources for scattered agency.

\section{§6.2: The Function of Exploration}

Mind wandering's second function may be to help us navigate the explore-exploit tradeoff (Sripada, 2018; Irving, 2019). Imagine that you are beginning to write an essay. Before you put pen to paper, you are faced with a choice. Should you pursue one of the ideas that you have already come up with? Or should you explore for a new idea? Explorers take a risk: you might waste precious time. But you might strike gold. This decision is an example of a fundamental tradeoff between two aims of a cognitive agent: to explore for new ideas, or to exploit the ideas we already have in order to get things done.

Humans arguably have different modes of thought that are tailored to the demands of exploitation and exploration (Sripada, 2018). Exploitative modes of thinking remain focused on our goals or personal concerns for extended periods of time and shield out distractions. You engage in exploitative thought, for example, when you successfully guide your attention to this article for long enough to get through a few pages. Exploitative thinking is necessary for limited agents like us. At any time, you can only focus on a tiny subset of all the relevant information. To make this subset count, you must be able to focus on what you think is relevant (e.g. this article) and ignore almost limitless things that might distract you.

several tasks can at any one time be at the forefront of one's mind, but there is no explicit commitment to keep any single task (or set of tasks) in focus. 


\section{METHODS IN MW RESEARCH}

Exploitation is an incomplete strategy, however, because you can be wrong about what is in fact relevant to you. Imagine that you dutifully guide your attention to this article, and nothing but, for a whole day. We the authors would be thrilled! But we recognize that you might miss out. Perhaps you would forget about other commitments that you have made. Or you might simply fail to expand the sphere or what you are reading and thinking about. By constantly guiding your attention to what you think is relevant, you risk being caught in a cognitive bubble, where you never notice the information that would lead you to expand your own point of view.

Exploratory modes of thought such as mind wandering may help us burst cognitive bubbles. When your mind drifts between topics, you may think of ideas that seem strange, useless, or irrelevant. This is not a bug of mind wandering, but a feature. For seemingly useless information can turn out to be crucial. Seemingly irrelevant ideas may be just what you need to expand your point of view. Mind wandering, then, may be an inbuilt mode of cognitive exploration that helps us take risks and search for new ideas. Most of the time, this exploration may prove useless. But sometimes it will strike gold.

\section{§6.3: Triangulation of Function and Method}

We have sketched two theories about the functions of mind wandering. First, mind wandering supports plural goal pursuit. Second, mind wandering supports cognitive exploration. Despite their differences, these theories generate common a priori predictions about the circumstances likely to elicit mind wandering. 


\section{METHODS IN MW RESEARCH}

Mind wandering should occur when we are bored or under-stimulated. Both of our functional theories contrast mind wandering with more focused forms of thinking, which occur when we are pursuing a single important goal (e.g. writing an exam or running from a tiger). We should therefore expect mind wandering to occur when people are bored, as boredom reflects a perceived lack of important information to extract from the task environment. Relatedly, we should expect strategic mind wandering in familiar and predictable task environments. Such environments are structured in ways where task performance does not benefit from sustained focus on the task (Kane et al., 2017). When engaged in boring or predictable tasks, we can free our cognitive resources to focus on the type of plural goal-pursuit and/or exploration characteristic of mind wandering (Geana, Wilson, Daw, \& Cohen, 2016).

Results from self-report studies are consistent with our a priori predictions about the circumstances likely to elicit mind wandering. For example, mind wandering is more frequent when people are bored, understimulated, or doing something either too easy or too difficult (Eastwood, Frischen, Fenske, \& Smilek, 2012). People report that mind wandering is more pleasant when they're doing something unengaging, which suggests that mind wandering relieves boredom (Mooneyham \& Schooler, 2013). The conditions that we expect to elicit mind wandering turn out to be the conditions where we observe a lot of mind wandering.

The fact that our best functional theories and self-report methods converge is reason to trust both theory and method. Consider an analogy. Imagine that we have two very different methods to estimate a quantity, such as the density of gold. Can we trust that our methods are accurate? Well, suppose 


\section{METHODS IN MW RESEARCH}

we find that each method is internally consistent: they yield the same measurements at different times and for different samples of gold. Suppose further that the methods are consistent with each other: both estimate the density at $19.32 \mathrm{~cm}^{3}$. Unless we have reason to think otherwise, the best explanation of this internal and external consistency is that a) the density of gold is $19.32 \mathrm{~cm}^{3}$ and b) both methods can accurately estimate this density. The fact that diverse methods triangulate onto a single answer gives us reason to trust both methods.

We think a similar form of triangulation gives us reason to trust selfreport methods in mind wandering science. Self-report methods are internally consistent, at least about the result that variables like boredom elevate mind wandering. Self-report methods are also consistent with independently plausible theories about the function of mind wandering. Put colloquially, one reason to believe self-reports about mind wandering is that they make sense.

Put more precisely, philosophical argumentation and self-report are both reliable methods for forming beliefs about mind wandering. These methods triangulate onto common claims about mind wandering: for example, that boring tasks elevate mind wandering. Unless we have reason to think otherwise, the best explanation for this triangulation is a) that mind wandering occurs more frequently in boring and undemanding tasks and b) that philosophical argumentation and self-report are both accurate.

We have focused on predictions about boredom. But triangulation has much broader application in the science of mind wandering. We can generate more consensus predictions from our best theories of the function of mind wandering. We can then see whether self-report methods yield results that make sense, given these predictions. If they do, this gives us defeasible reason to trust 


\section{METHODS IN MW RESEARCH}

that self-reports about mind wandering are accurate. Mind wandering science may be unable to do without self-report. But our trust in self-report can be based in theory, rather than blindness.

\section{Conclusion}

Mind wandering science cannot do without self-report. At best, objective measures complement self-report methods, but do not replace them. This is not a defect of mind wandering research, but a reflection of the kind of cognitive state mind wandering is: a passive manifestation of agency. We suspect that there are many other passive manifestations of agency that are inaccessible to purely taskbased methodologies. As such, research on mind wandering provides valuable lessons on how to refine self-report methodologies and use them in conjunction with more standard methods in cognitive psychology and neuroscience.

Skeptics about the reliability of self-report may take this as reason to doubt mind wandering science. Our response to the skeptic appeals to the metaphysics of mind wandering to partially vindicate self-report methods. This response highlights how theoretical models play an important role in verifying the accuracy of experimental methods. When the outputs of these methods (data) converge with the predictions of the model, this is crucial evidence for the validity of empirical methods. Convergence, then, also provides evidence in favor of the model. The justificatory pathway between theory and data runs both ways. This runs contrary to a tendency in cognitive psychology to separate theory and data, with data being considered the only source of evidence. Theories, on this view, might make predictions that guide the acquisition of data, but theories themselves are not considered sources of evidence. Our argument 


\section{METHODS IN MW RESEARCH}

depends on this being wrong; instead, the theoretical content of and argument for a model both play important roles in verifying both methods and the model itself. This is consistent with a model-based view of scientific methodology that began to flourish as a reaction against the logical positivism of the $20^{\text {th }}$ century (see Kuhn, 1962; Feyerabend, 1969; Tal, 2011).

While this is a longer story than we have space here to tell, we want to highlight the fact that, on our view, philosophical theorizing plays an important role in generating evidence insofar as such theorizing can produce models. Our argument is one example of this. The functional characterizations of mind wandering offered above are drawn from philosophical reflections on mind wandering, attention, and action. This suggests that philosophers have a more active role to play in empirical inquiry than simply double-checking the inferences that cognitive scientists make. 


\section{REFERENCES}

Adams, R.M. 1985. “Involuntary Sins,” The Philosophical Review 94, 1-31.

Antrobus, J.S. 1968. Information theory and stimulus-independent thought. Bristish Journal of Psychology 59, 423-430.

Amaya, S. \& Murray, S. Under review. Vigilance.

Arango, S. \& Bermúdez, J.P. Manuscript. Intentional Mind-Wandering as Intentional Omission: The Surrealist Method.

Audi, R. 1979. Wants and intentions in the explanation of action. Journal for the Theory of Social Behaviour 9:3, 227-249.

Baddeley, A.D., and Hitch, G. 1974. "Working memory," In G.H. Bower (ed.) The psychology of learning and motivation, vol. 8 (New York: Academic Press), 47-89.

Baird, B., Smallwood, J., Mrazek, M.D., Kam, J.W., Franklin, M.S., \& Schooler, J.W. 2012. Inspired by distraction: Mind wandering facilitates creative incubation. Psychological Science 23, 1117-22.

Baird, B., Smallwood, J., Schooler, J.W. 2011. Back to the future: autobiographical planning and the functionality of mind-wandering. Consciousness $\mathcal{E}$ Cognition 20, 1604-11.

Baird, B., Smallwood, J., Lutz, A., \& Schooler, J.W. 2014. The decoupled mind: Mind-wanering disrupts cortical phase-locking to perceptual events. Journal of Cognitive Neuroscience 26, 2596-2607.

Barron, E., Riby, L.M., Greer, J., \& Smallwood, J. 2011. Absorbed in thought: the effect of mind wandering on the processing of relevant and irrelevant events. Psychological Science 22, 596-601.

Bastian, M., Sackur, J.. 2013. Mind wandering at the fingertips: automatic parsing of subjective states based on response time variability. Front Psychol. 4:573.

Published 2013 Sep 5. doi:10.3389/ fpsyg.2013.00573

Binder, J.R., Frost, J.A., Hammeke, T.A., Bellgown, P.S.F., Rao, S.M., \& Cox, R.W. 1999. Conceptual processing during the conscious resting state: a functional MRI study. Journal of Cognitive Neuroscience 11:1, 80-93.

Bixler, R., Blanchard, N., Garrison, L., \& D'Mello, S. 2015. Automatic detection of mind wandering during reading using gaze and physiology. ICMI '15:

Proceedings of the 2015 ACM International Conference on Multimodal Interaction, 299306. https: / / doi.org/10.1145/2818346.2820742. 


\section{METHODS IN MW RESEARCH}

Brosowsky, N.P., Murray, S., Schooler, J.W., \& Seli, P. Under review. Attention need not always apply: Mind wandering impedes explicit but not implicit sequence learning.

Buckner, R.L., Andrews-Hanna, J.R., \& Schacter, D.L. 2008. The brain's default network: anatomy, function, and relevance to disease. Annals of the New York Academy of Sciences 1124: 1-38.

Callard, F., Smallwood, J., \& Margulies, D. S. 2011. “Default positions: How neuroscience's historical legacy has hampered investigation of the resting mind" Frontiers in Psychology, 3: 321.

Christoff, K., Gordon, A.M., Smallwood, J., Smith, R., \& Schooler, J.W. 2009.

Experience sampling during fMRI reveals default network and executive system contributions to mind wandering. Proceedings of the National Academy of Sciences USA 106, 8719-24.

Christoff, K., Irving, Z. C., Fox, K. C. R., Spreng, R. N., \& Andrews-Hanna, J. R. 2016. "Mind wandering as spontaneous thought: a dynamic framework" Nature Reviews. Neuroscience. Neuroscience, 17(11), 718-731.

Cullen, S. 2010. Survey-driven romanticism. Review of Philosophy and Psychology 1, 275-96.

D'Mello, S. K., Mills, C., Bixler, R., \& Bosch, P. N. (2017). Zone Out No More: Mitigating Mind Wandering During Computerized Reading. Paper presented at 2017 International Conference on Educational Data Mining, Wuhan, China.

Dang, J. 2018. An updated meta-analysis of the ego depletion effect. Psychological Research 82:4, 645-51.

Eastwood, J.D., Frischen, A., Fenske, M.J., \& Smilek, D. 2012. The unengaged mind: Defining boredom in terms of attention. Perpsectives on Psychological Science 7:5, 482-95.

Faber, M., Bixler, R., and D'Mello, S.K. 2018. “An automated behavioral measure of mind wandering during computerized reading," Behavior Research Methods 50, 134-50.

Faber, M., Krasich, K., Bixler, R.E., Brockmole, J.R., \& D’Mello, S.K. In press. The eye-mind wandering link: Identifying gaze indices of mind wandering across tasks. Journal of Experimental Psychology: Human Perception and Performance.

Feng, S., D'Mello, S., \& Graesser, A.C. 2013. Mind wandering while reading easy and difficult texts. Psychonomic Bulletin \& Review 20, 586-92. 


\section{METHODS IN MW RESEARCH}

Feyerabend, P.K., 1969, "Science Without Experience," in P.K.

Feyerabend, Realism, Rationalism, and Scientific Method (Philosophical Papers I), Cambridge: Cambridge University Press, 1985, pp. 132-136.

Forrin, N.D., Risko, E.F., \& Smilek, D. 2019. On the relation between reading difficulty and mind-wandering: a section-length account. Psychological Research 83:3, 485-97.

Foulsham, T., Farley, J., Kingstone, A. 2013. Mind wandering in sentence reading: decoupling the link between mind and eye. Canadian Journal of Experimental Psychology 67, 51-59.

Fox, K.C.R., Spreng, R.N., Ellamil, M., Andrews-Hanna, J.R., and Christoff, K. (2015) "The wandering brain: Meta-analysis of functional neuroimaging studies of mind wandering and related spontaneous thought processes" Neuroimage 111 $611-621$.

Frank, D.J., Nara, B., Zavagnin, M., Touron, D.R., \& Kane, M.J. (2015). Validating older adults' reports of less mind-wandering: An examination of eye-movements and dispositional influences. Psychology and Aging, 30(2), 266-278. DOI: 10.1037 / pag0000031

Franklin, M.S., Mrazek, M.D., Anderson, C.L., Smallwood, J., Kingstone, A., \& Schooler, J.W. 2013-a. The silver lining of a mind in the clouds: interesting musings are associated with positive mood while mind-wandering. Frontiers in Psychology 4:583. Doi:10.3389/fpsyg.2013.00583

Franklin, M.S., Broadway, J.M., Mrazek, M.D., Smallwood, J., \& Schooler, J.W. 2013-b. Window to the wandering mind: pupillometry of spontaneous thought while reading. Quarterly Journal of Experimental Psychology (Hove) 66, 2289-94.

Gable, S.L., Hopper, E.A., \& Schooler, J.W. 2019. When the Muses Strike: Creative Ideas of Physicists and Writers Routinely Occur During Mind Wandering. Psychological Science 30:3, 396-404.

Geana, A., Wilson, R., Daw, N.D., \& Cohen, J. 2016. Boredom, informationseeking and exploration. In A. Papafragou, D. Grodner, D. Mirman, \& J.C. Trueswell (Eds.) Proceedigns of the Cognitive Science Society (Austin, TX: Cognitive Science Society), 1751-56.

Giambra, L.M. 1995. A laboratory method for investigating influences on switching attention to task-unrelated imagery and thought. Consciousness $\mathcal{E}$ Cognition 4:1, 1-21.

Gil-Jardiné C, Née M, Lagarde E, Schooler J, Contrand B, Orriols L, et al. (2017) The distracted mind on the wheel: Overall propensity to mind wandering is associated with road crash responsibility. PLoS ONE 12(8): e0181327. https: / / doi.org/10.1371/journal.pone.0181327. 


\section{METHODS IN MW RESEARCH}

Gorgolewski, K.J., Lurie, D., Urchs, S., Kipping, J.A., Craddock, R.C. et al. 2014. A correspondence between individual differences in the brain's intrinsic functional architecture and the content and form of self-generated thoughts. PLOS ONES 9:e97176.

Green, S. 2010. Consciousness and Ian McEwan's Saturday: “What Henry Knows". English Studies 91:1, 58-73.

Hall, L., Johansson, P., \& Strandberg, T. (2012). Lifting the veil of morality: Choice blindness and attitude reversals on a self-transforming survey. PLoS ONE, 7(9), Article e45457.

Hillyard, S.A., Hink, R.F., Schwent, V.L., \& Picton, T.W. Electrical signs of selective attention in the human brain. Science 182:4108, 177-80.

Hutt, S., Krasich, K., Mills, C., Bosch, N., White, S., Brockmole, J. R., \& D’Mello, S. K. (2019). Automated gaze-based mind wandering detection during computerized learning in classrooms. User Modeling and User-Adapted Interaction 29, 821-67.

Irving, Z.C. 2016. "Mind wandering is unguided attention: accounting for the 'purposeful' wanderer," Philosophical Studies 173, 547-71.

Irving, Z.C. 2018. "Psychology Off Tasks," Journal of Consciousness Studies 25:5-6, 63-84.

Irving, Z. C. (2019). Attention norms in Siegel's The Rationality of Perception. Ratio 32:1, 84-91.

Irving, Z.C. Under review. Drifting and directed minds: The significance of mind-wandering for mental action. Available at PhilPapers:

https: / / philpapers.org/ rec/IRVDAD.

Irving, Z.C., Glasser, A., Gopnik, A., \& Sripada, C. Under review. What does "mind-wandering" mean to the folk? An empirical investigation. Available on PsyArxiv: https: / / psyarxiv.com/su2qj/

Israel, M.M., Jolicoeur, P., \& Cohen, A. 2018. The effect of pre-cueing on spatial attention across perception and action. Psychonomic Bulletin E Review 25:2, 18401846.

Juhasz, B. J., \& Rayner, K. (2006). The role of age of acquisition and word frequency in reading: Evidence from eye fixation durations. Visual Cognition, 13(7-8), 846-863.

Just, M.A. \& Carpenter, P.A. 1976. Eye fixations and cognitive processes. Cognitive Psychology 8:4, 441-80. 


\section{METHODS IN MW RESEARCH}

Kam, J.W.Y., Dao, E., Farley, J., Fitzpatrick, K., Smallwood, J., Schooler, J.W., \& Handy, T.C. 2011. Slow fluctuations in attentional control of sensory cortex. Journal of Cognitive Neuroscience 23:2, 460-70.

Kane, M.J., Brown, L.H., McVay, J.C., Silvia, P.J., Myin-Germeys, I., and Kwapil, T. R. 2007. "For whom the mind wanders, and when: an experience-sampling study of working memory and executive control in daily life" Psychological Science 18: 7, 614-621.

Kane, M.J. \& McVay, J.C. 2012. What mind wandering reveals about executivecontrol abilities and failures. Current Directions in Psychological Science 21, 348-54.

Kane, M.J., Gross, G.M., Chun, C.A., Smeekens, B.A., Meier, M.E., Silvia, P.J., Kwapli, T.R. 2017. For whom the mind wanders, and when, varies across laboratory and daily-life settings. Psychological Science 28:9, 1271-1289.

Killingsworth, M.A. \& Gilbert, D.T. 2010. A wandering mind is an unhappy mind. Science 330:6006, 932.

Klein, C. 2012. Cognitive Ontology and Region- versus Network-Oriented Analyses. Philosophy of Science 79:5, 952-60.

Klinger, E. 2013. Goal commitments and the content of thoughts and dreams: basic principles. Frontiers in Psychology 4:415.

Kopp, K., D’Mello, S., \& Mills, C. 2015. Influencing the occurrence of mind wandering while reading. Consciousness $\mathcal{E}$ Cognition 34, 52-62.

Kowler, E., Anderson, E., Dosher, B., \& Blaser, E. 1995. The role of attention in the programming of saccades. Vision Research 35:13, 1897-916.

Krasich, K., McManus, R., Hutt, S., Faber, M., D’Mello, S.K., and Brockmole, J.R. 2018. "Gaze-based signatures of mind wandering during real-world scene processing," Journal of Experimental Psychology: General 147:8, 1111-24.

Krimsky, M., Forster, D. E., Llabre, M. M., \& Jha, A. P. (2017). The influence of time on task on mind wandering and visual working memory. Cognition, 169, 8490.

Kuhn, T.S., The Structure of Scientific Revolutions, 1962, Chicago: University of Chicago Press

Lappin, J.S,. and Eriksen, C.W. 1966. Use of a delayed signal to stop a visual reaction-time response. Journal of Experimental Psychology 72 (6):805.

Logan, G. D. (2015). The point of no return: A fundamental limit on the ability to control thought and action. Quarterly Journal of Experimental Psychology, 68, 833-857. 


\section{METHODS IN MW RESEARCH}

Lutz, A., Slagter, H. A., Dunne, J. D., \& Davidson, R. J. 2008. Attention regulation and monitoring in meditation. Trends in Cognitive Sciences, 12(4), 163-169.

Mason, M.F., Norton, M.I., Van Horn, J.D., Wegner, D.M., Grafton, S.T., \& Macrae, C.N. 2007. Wandering minds: the default network and stimulusindependent thought. Science 315, 393-95.

Mazoyer, P., Zago, L., Mallet, E., Bricogne, S., Etard, O., Houde, O., Crivello, F., Joliot, M., Petit, L., Tzourio-Mazoyer, N. 2001. Cortical networks for working memory and executive function sustain the conscious resting state in man. Brain Research Bulletin 54, 287-98.

McVay, J.C. \& Kane, M.J. 2009. Conducting the train of thought: working memory capacity, goal neglect, and mind wandering in an executive-control task. Journal of Experimental Psychology: Learning, Memory, E Cognition 35, 196-204.

McVay, J.C. \& Kane, M.J. 2010. Does mind wandering reflect executive function or executive failure? Comment on Smallwood and Schooler 2006 and Watkins 2008. Psychological Bulletin 136, 188-97.

McVay, J.C. \& Kane, M.J. 2011. Why does working memory capacity predict variation in reading comprehension? On the influence of mind wandering and executive attention. Journal of Experimental Psychology: General 141, 302-20.

Miller, G.A. 1956. The magical number seven, plus or minus two: Some limits on our capacity for processing information. Psychological Review 63, 81-97.

Mills, C., Rafaelli, Q., Irving, Z.C., Stan, D., and Christoff, K. 2018. "Is an off-task mind a freely-moving mind? Examining the relationship between different dimensions of thought," Consciousness $\mathcal{E}$ Cognition 58, 20-33.

Mooneyham, B.W. \& Schooler, J.W. 2013. The costs and benefits of mindwandering: a review. Canadian Journal of Experimental Psychology, 67:11-18.

Mills, C., Gregg, J., Bixler, R., \& D’Mello, S.K. 2020. Eye-mind reader: an intelligent reading interface that promotes long-term comprehension by detecting and responding to mind wandering. Human-Computer Interaction, 1-27.

Murray, S. and Krasich, K. In Press. "Can the Mind Wander Intentionally?" Mind $\mathcal{E}$ Language.

Murray, S., Krasich, K., Schooler, J.W., and Seli, P. In Press. "What's in a Task? Complications in the Study of the Task-Unrelated-Thought (TUT) Conception of Mind Wandering," Perspectives on Psychological Science.

Posner, M. I. (1980). "Orienting of attention" Quarterly Journal of Experimental Psychology. 31, 1: 3-25.

Preiss, D.D., Cosmelli, D., Grau, V., \& Ortiz, D. 2016. Examining the influence of mind wandering and metacognition on creativity in university and vocational students. Learning and Individual Differences 51. 417-426. 


\section{METHODS IN MW RESEARCH}

Raichle, M.E. 2015. The brain's default mode network. Annual Review of Neuroscience 38, 433-47.

Rayner, K. \& Duffy, S.A. 1986. Lexical complexity and fixation times in reading: Effects of word frequency, verb complexity, and lexical ambiguity. Memory $\mathcal{E}$ Cognition 14, 191-201.

Reichle, E.D., Rayner, K., \& Pollatsek, A. 2003. The E-Z reader model of eyemovement control in reading: comparisons to other models. Behavioral $\mathcal{E}$ Brain Sciences 26:4, 445-76.

Reichle, E.D., Reineberg, A.E., \& Schooler, J.W. 2010. Eye movements during mindless reading. Psychological Science 21:9, 1300-1310.

Robertson, I.H., Manly, T., Andrade, J., Baddeley, B.T., \& Yiend, J. 1997. “Oops!”: Performance correlates of everyday attentional failures in traumatic brain injured and normal subjects. Neuropsychologia 35, 747-758.

Robins, R. W., \& John, O. P. (1997). The quest for self-insight: Theory and research on accuracy and bias in self-perception. In R. Hogan, J. A. Johnson, \& S. R. Briggs (Eds.), Handbook of personality psychology (p. 649-679). Academic Press.

Robison, M. K., Miller, A. L., \& Unsworth, N. (2019). Examining the effects of probe frequency, response options, and framing within the thought-probe method. Behavior research methods, 51(1), 398-408.

Schooler, J.W., Reichle, E.D., \& Halpern, D.V. 2004. Zoning out while reading: Evidence for dissociations between experience and metaconsciousness. In D.T. Levin (Ed.), Thinking and seeing: Visual metacognition in adults and children (pp. 203-226). Cambridge, MA: MIT Press.

Schooler, J.W., Smallwood, J., Christoff, K., Handy, T.C., Reichle, E.D., \& Sayette, M.A. 2011. Meta-awareness, perceptual decoupling and the wandering mind. Trends in Cognitive Sciences 15:7, 319-26.

Schwitzgebel, E. 2008. "The unreliability of naïve introspection," Philosophical Review 117:2, 245-73.

Seli, P., Carriere, J.S.A., Levene, M., and Smilek, D. 2013. “How few and far between? Examining the effects of probe rate on self-reported mind wandering," Frontiers in Psychology 4, 430.

Seli, P., Cheyne, J.A., \& Smilek, D. 2013. Wandering minds and wavering rhythms: Linking mind wandering and behavioral variability. Journal of Experimental Psychology: Human Perception E Performance 39, 1-5.

Seli, P., Smallwood, J., Cheyne, J.A., \& Smilek, D. 2015. On the relation of mind wandering and ADHD symptomatology. Psychonomic Bulletin E Review 22:3, 629636. 


\section{METHODS IN MW RESEARCH}

Seli, P., Risko, E.F., \& Smilek, D. 2016. On the necessity of distinguishing between unintentional and intentional mind wandering. Psychological Science 27:5, 685-91.

Seli, P., Risko, E.F., Smilek, D., \& Schacter, D.L. 2016. Mind-wandering with and without intention. Trends in Cognitive Sciences 20:8, 605-17.

Seli, P., Beaty, R.E., Cheyne, J.A., Smilek, D., Oakman, J., \& Schacter, D.L. 2018. How pervasive is mind wandering, really? Consciousness $\mathcal{E}$ Cognition 66, 74-78.

Seli, P., Carriere, J.S.A., Wammes, J.D., Risko, E.F., Schacter, D.L., \& Smilek, D. 2018. On the Clock: Evidence for the Rapid and Strategic Modulation of Mind Wandering. Psychological Science 29:8, 1247-56.

Seli, P., Kane, M.J., Smallwood, J., Schacter, D.L., Maillet, D., Schooler, J.W., and Smilek, D. 2018. "Mind wandering as a Natural Kind: A Family-Resemblances View," Trends in Cognitive Sciences 22:6, 479-490.

Shenhav, A., Musslick, S., Lieder, F., Kool, W., Griffiths, T.L., Cohen, J.D., Botvinick, M.M. 2017. Toward a rational and mechanistic account of mental effort. Annual Review of Neurosciences 40, 9-124.

Shulman, G.L., Corbetta, M., Fiez, J.A., Buckner, R.L., Miezin, F.M., Raichle, M.F., \& Petersen, S.F. 1997. Searching for activations that generalize over tasks. Human Brain Mapping 5:4, 317-22.

Sinnott-Armstrong, W. 2008. Framing moral intuitions. In W. Sinnott-Armstrong (Ed.), Moral Psychology, Vol. 2. The cognitive science of morality: Intuition and diversity (pp. 47-76). MIT Press.

Smallwood, J. 2013. Distinguishing how from why the mind wanders: a processoccurrence framework for self-generated thought. Psychological Bulletin 139, 51935.

Smallwood, J., Beach, E., Schooler, J.W., \& Handy, T.C. 2008. Going AWOL in the brain: mind wandering reduces cortical analysis of external events. Journal of Cognitive Neuroscience 20, 458-469.

Smallwood, J., Fitzgerald, A., Miles, L.K., \& Phillips, L.H. 2009. Shifting moods, wandering minds: negative moods lead the mind to wander. Emotion 9, 271-276.

Smallwood, J. \& Schooler, J.W. 2015. The Science of Mind Wandering: Empirically Navigating the Stream of Consciousness. Annual Reviews in Psychology 66, 487-518.

Smilek, D., Carriere, J. S. A., \& Cheyne, J. A. (2010). Out of mind, out of sight: Eye blinking as indicator and embodiment of mind wandering. Psychological Science, 21(6), 786-789. 


\section{METHODS IN MW RESEARCH}

Smith, A., Brosowsky, N.P., Murray, S., \& Seli, P. Under review. Testing the predictions of the Dynamic Framework of mind wandering.

Sorensen, R.A. 1985. Self-deception and scattered events. Mind 94:373, 64-69.

Spreng, N., Stevens, W. D., Chamberlain, J.P., Gilmore, A.W., and Schacter, D.L. (2010) "Default network activity, coupled with the frontoparietal control network, supports goal-directed cognition" Neuroimage 53:1, 303-317.

Spruyt, K., Herbillon, V., Putois, B. et al. 2019. Mind-wandering, or the allocation of attentional resources, is sleep-driven across childhood. Scientific Reports 9, 1269. https: / / doi.org/10.1038/s41598-018-37434-5.

Sripada, C. 2018. “An Exploration/Exploitation Tradeoff Between Mind Wandering and Task-Directed Thinking" In K. C. R. Fox \& K. Christoff (Eds.), Oxford Handbook of Spontaneous Thought and Creativity. Oxford University Press.

Stalnaker, R. 1984. Inquiry (Cambridge, MA: MIT Press).

Steindorf, L. \& Rummel, J. 2020. Do your eyes give you away? A validation study of eye-movement measures used as indicators for mindless reading. Behavioral Research Methods 52:1, 162-76.

Tal, E. 2011. How Accurate is the Standard Second? Philosophy of Science 78:5, 1082-96.

Thomson, D.R., Besner, D., \& Smilek, D. 2015. A resource-control account of sustained attention: evidence from mind-wandering and vigilance paradigms. Perspectives in Psychological Science 10:1, 82-96.

Thomson, D.R., Seli, P., Besner, D., \& Smilek, D. 2014. On the link between mind wandering and task performance over time. Consciousness $\mathcal{E}$ Cognition 27, 14-26.

Uzzaman, S. and Joordens, S. 2011. "The eyes know what you are thinking: eye movements as an objective measure of mind wandering," Consciousness $\mathcal{E}$ Cognition, 20:4, 1882-86.

van Fraassen, B. (1984). "Belief and the Will." The Journal of Philosophy, 81: 5, 235256.

van Inwagen, P. 1989. When is the Will Free? Philosophical Perspectives 3, 399-422.

Wang, Y., Xu, W., Zhuang, C., \& Liu, X. 2017. Does mind wandering mediate the association between mindfulness and negative mood? A preliminary study. Psychological Reports 120(1), 118-129.

Warm, J.S., Parasuraman, R., \& Matthews, G. 2008. Vigilance requires hard mental work and is stressful. Human Factors 50:3, 433-441. 


\section{METHODS IN MW RESEARCH}

Wegner, D.M. 1997. Why the mind wanders. In J.D. Cohen \& J.W. Schooler (Eds.), Scientific approaches to consciousness (pp. 295-315). Mahwah, NJ: Erlbaum.

Windt, J. 2015. Dreaming: A conceptual framework for philosophy of mind and empirical research. MIT Press.

Windt, J. 2016. Dreaming, imagining, and first-person methods in philosophy: Commentary on Evan Thompson's Waking, Dreaming, Being. Philosophy East $\mathcal{E}$ West 66:3, 959-81.

Yanko, M.R. \& Spalek, T.M. 2014. Driving with the wandering mind: the effect that mind-wandering has on driving performance. Human Factors 56:2, 260-69.

Yarkoni, T. \& Westfall, J. 2017. Choosing prediction over explanation in psychology: lesson from machine learning. Perspectives on Psychological Science $12: 6,1100-1122$.

Zedelius, C.M., Broadway, J.M., and Schooler, J.W. 2015. "Motivating metaawareness of mind wandering: A way to catch the mind in flight?" Consciousness $\mathcal{E}$ Cognition 36, 44-53. 